compelling narratives necessary for the future success of the hospice movement.

Conclusion Sharing these narratives at the Hospice UK Conference will provide an opportunity for the wider hospice sector to react and help shape the story that will inform the future leadership aspirations of a new cohort of hospice leaders.

\section{P-250 LEADING TRANSFORMATION IN A PERFECT STORM: TESTING THE THEORIES THROUGH A LIVED EXPERIENCE}

Tina Swani. Birmingham St Mary's Hospice, Birmingham, UK

\subsection{6/bmjspcare-2016-001245.271}

The presentation delivers a lived experience over 15 months from a point where three significant risks simultaneously materialised in November 2014, to a position where eight service redesign projects were launched by April 2016 with recognised impact on larger systems transformation. The financial position shifted from an anticipated deficit of $£ 1 \mathrm{~m}$ to a surplus of almost $£ 0.5 \mathrm{~m}$.

The presentation relates and reframes culture, coaching, change and marketing theory whilst delivering learning from mistakes and successes; how change was accelerated once the shift from fear to possibility was achieved; and how the focus on dignity, experience and confidence of patients, families and carers has extended reach as a result.

In November 2014 three events occurred:

- Legacy income had not materialised during September, October and November

- Three Clinical Commissioning Groups initiated a procurement process for End of Life Care

- The Fundraising teams were in the middle of a major uplift with an anticipated decline in income trajectory on the previous year

Whilst each risk had been anticipated in isolation, together, this created a perfect storm.

The author delivers a real story, illustrating how change was accelerated through self-directing teams that have transformed working practice to enter new market space with a tested target to double reach and demonstrate sustainability through the Hospice's Case for Change.

The Case for Change has already achieved significant financial investment (including CCG and major donor investment); early review to the CCG demonstrates some evidence of larger system transformation.

\section{P-251 A TAILORED APPROACH TO VOLUNTEER LEARNING AND DEVELOPMENT}

Morven MacLean. Children's Hospice Association Scotland (CHAS), Edinburgh, UK

\subsection{6/bmjspcare-2016-001245.272}

Having a well-informed, skilled and motivated volunteer force enables us to deliver the best possible service to children, young people and their families. Like most hospices, our organisation requires staff and volunteers to undertake statutory/mandatory training in order to ensure the safety of its' people and the quality of services delivered to children, young people and their families.

We have adopted a tailored and inclusive approach to volunteer learning and development. Volunteers receive relevant content, appropriate to their role, and it is delivered in a format that is cost-effective, accessible and scalable. The development of a core learning matrix and e-learning platform unique to volunteers was developed by the Voluntary Services Team in conjunction with volunteers.

This provided a solution to the volunteer statutory/mandatory learning dilemma - balancing legislative requirements with a volunteer engagement and inclusion agenda. Volunteers complete a short learning package that is accessible, tailored and proportional to the level of risk attached to their role. Statutory/mandatory training has been rebranded as volunteer core learning and assessments that had in the past provoked anxiety have been removed.

A communications plan shared with staff ensured consistent positive messaging to volunteers and volunteer communications clearly sold the benefits of the new system to volunteers. The matrix and e-learning platform were launched with volunteers in April 2016 and feedback to date has been excellent. Our organisation now has an approach to volunteer core learning that complements the direction of travel in volunteer engagement. Lack of time and too much bureaucracy are well-documented barriers to volunteering. Both these barriers have been addressed by this project.

Our organisation has received a lot of interest from other hospices in our volunteer core learning matrix which is why we are keen to share this piece of work more widely at the Hospice UK conference.

\section{P-252 ABSTRACT WITHDRAWN}

\section{P-253 'THINKING INSIDE THE BOX' - PRISONERS AS VOLUNTEERS?}

Katherine Bright. Earl Mountbatten Hospice, Newport, UK

\subsection{6/bmjspcare-2016-001245.273}

Introduction Firm geographical boundaries between yourself and competitors can often be beneficial but when you live on an Island it can make things difficult when in need of resources such as volunteers.

Aims of the project Expand the volunteer role to encompass the workforce available at HMP and to provide meaningful tasks that engage prisoners with the local community in a positive manner. Approach used Lots of meetings with HMP to work through as many options as possible to engage the workforce with a range of projects: recycling of newspapers into bags, upcycling furniture, and production of concrete garden ornaments and hanging/sizing/steaming of clothing.

Working together through the processes and procedures required when dealing with a high security environment.

Promotion of the project was important and branding and signage has been developed to inform and engage customers.

Results Fortnightly deliveries/collections to HMP allow sufficient time for processing items in the various workshops and different projects. Financially we both benefit with different remuneration for different items. Community engagement is positive with customers timing their visits to our shops to coincide with deliveries of the latest stock. The prisoners look forward to receiving before and after photos of the upcycled items and are making a display in the workshop to encourage participation from others and increasing the drive to learn more skills and take on increasingly difficult items. 
Conclusion The best solutions are often simple, yet unexpected Julian Casablancas

Although it took time to sort out the processes required it is now routine and as easy as outsourcing to any supplier. The initial reluctance of some to involve with HMP was quickly overcome and very positively received by our community. I would encourage everyone to look locally for solutions; in a world that has become smaller through the internet we often lose sight of the skills and opportunities right under our noses.

\section{P-254 SEVENTEEN AND SUPER KEEN; YOUNG PEOPLE VOLUNTEERING ON AN IN-PATIENT UNIT}

Clair Sadler, Zoe Byrne. Princess Alice Hospice, Esher, UK

\subsection{6/bmjspcare-2016-001245.274}

In September 2015, we introduced an innovative new volunteering programme aimed at 17 -year-olds interested in a career in healthcare. The Ward Support Volunteers committed to a unique six-month programme involving supporting healthcare assistants on our large in-patient unit and working towards the Care Certificate qualification.

The objectives were to:

- create a sustainable programme that increased resource on the in-patient unit

- provide a meaningful opportunity for young people interested in healthcare

- diversify the volunteer workforce.

The role description included talking with patients and relatives, assisting with meals and drinks and replenishing stock. All local schools and colleges were contacted to publicise the opportunity and 22 young people were interviewed.

The Education team delivered a bespoke experiential induction day for the 14 selected volunteers that explored communication skills as well as practical training like hand massage.

We also developed a workbook to accredit the programme under the new Care Certificate which included practical activities and online learning. Experienced volunteers acted as 'Buddies', regularly meeting with the young volunteers to support them.

Thirteen young people completed the programme and received the Care Certificate. The main gain for the volunteers, however, was an increase in their confidence and ability to communicate.

"I don't think I would have got medicine offers without it but, more importantly, it has made me a much more confident and compassionate person.” Robyn, 17

"The ward support volunteers have been a fantastic addition to the ward. They inject some much needed energy when they arrive at $4.30 \mathrm{pm}$ and to have enthusiastic, inquisitive young people on the ward has benefited the staff as well as the patients and visitors." Senior Staff Nurse

The programme continues with the second cohort also being trained in basic manual handling to make their role even more valuable to the ward.

\section{P-255 BUILDING PARTNERSHIPS BY DEVELOPING A VOLUNTEERING STRATEGY}

Katherine Perrin. St Catherine's Hospice, Crawley, UK
Introduction McCurley, Lynch and Jackson (2012) suggest that volunteers are an underused resource and that volunteers can and should make a significant contribution to an organisation's strategic objectives. St Catherine's currently has more than 800 volunteers.

Aim To set the strategic direction for volunteering, recognising the central role volunteers play in the delivery of services and support functions. A compelling and collaborative vision was needed to unite all services behind the ambition to enhance how we recruit, induct, value, celebrate, and develop volunteers, as well as innovating how they are included in the delivery of our services.

Method In 2014-15 every line manager across the organisation was consulted, exploring strengths, challenges and ambitions. The volunteer development manager shadowed existing volunteers, analysed how well we articulate our vision and the appetite for revolutionising our approach. Finally a gap analysis of our position against key national standards, including Investing in Volunteers, was undertaken to benchmark our approach.

Having established our baseline and emerging themes, our objectives and key activities were drafted. All volunteers were consulted via email and a breakfast event. Feedback was used to consolidate these objectives, create a vision and flesh out key activities. The project group of managers and a volunteer representative were asked to review the full draft before Senior Management signed off the strategy.

Results The organisation's first ever Volunteering Strategy was published in the summer of 2015. It recognises that volunteers are some of the biggest donors to the hospice and their time is priceless. It sets out an ambitious vision to be the organisation of choice for volunteers - to hold a reputation of volunteering excellence and demonstrate best practice in all that it does.

\section{P-256 DEVELOPING OUR PEOPLE - ESTABLISHING A NEW TRAINING PROGRAMME FOR VOLUNTEERS}

Katherine Perrin. St Catherine's Hospice, Crawley, UK

\subsection{6/bmjspcare-2016-001245.276}

Introduction Skogland suggests that effective training "results in volunteers' willingness to participate in the agency's volunteer program for a significant period of time” (Skogland 2006).

Aim To invest in our $800+$ volunteers by delivering essential training, to refresh key skills and competencies, improve confidence and encourage volunteers to share and gain new expertise. Method Of our four categories of volunteer (clinical, non-clinical, retail and community), we prioritised clinical and set up a project group of clinical managers and the volunteering development manager. Content was influenced by legal and policy requirements, general information for all volunteers and specific competencies needed, with managers leading on their skill areas.

During the day, volunteers explored the challenges of communicating, safeguarding, setting boundaries and volunteering safely. Working through scenarios and practical exercises, volunteers learnt from clinicians as well as each other, with a strong focus on insights into life as a patient.

One important aim is to transform all hospice volunteers into Dementia Friends, and this work will create more than 240 new Dementia Friends supporting our work and using this knowledge in their everyday lives. 